\title{
Larvicidal activity of neem oil (Azadirachta indica) formulation against mosquitoes
}

\author{
Virendra K Dua*1, Akhilesh C Pandey ${ }^{1}$, Kamaraju Raghavendra ${ }^{2}$, \\ Ashish Gupta ${ }^{1}$, Trilochan Sharma ${ }^{1}$ and Aditya P Dash ${ }^{2}$
}

Address: ${ }^{1}$ National Institute of Malaria Research, Field Unit, Sector-III, BHEL, Hardwar 249043, India and ${ }^{2}$ National Institute of Malaria Research, 22 Sham Nath Marg, Delhi 110054, India

Email: Virendra K Dua* - vkdua51@gmail.com; Akhilesh C Pandey - acpandey62@gmail.com;

Kamaraju Raghavendra - kamarajur2000@yahoo.com; Ashish Gupta - gupta4268@gmail.com; Trilochan Sharma - trilochan79@gmail.com; Aditya P Dash - apdash2@rediffmail.com

* Corresponding author

Published: 8 June 2009

Malaria Journal 2009, 8:124 doi:10.1186/1475-2875-8-124
Received: 8 March 2009

Accepted: 8 June 2009

This article is available from: http://www.malariajournal.com/content/8/I//24

(C) 2009 Dua et al; licensee BioMed Central Ltd.

This is an Open Access article distributed under the terms of the Creative Commons Attribution License (http://creativecommons.org/licenses/by/2.0), which permits unrestricted use, distribution, and reproduction in any medium, provided the original work is properly cited.

\begin{abstract}
Background: Mosquitoes transmit serious human diseases, causing millions of deaths every year. Use of synthetic insecticides to control vector mosquitoes has caused physiological resistance and adverse environmental effects in addition to high operational cost. Insecticides of botanical origin have been reported as useful for control of mosquitoes. Azadirachta indica (Meliaceae) and its derived products have shown a variety of insecticidal properties. The present paper discusses the larvicidal activity of neem-based biopesticide for the control of mosquitoes.
\end{abstract}

Methods: Larvicidal efficacy of an emulsified concentrate of neem oil formulation (neem oil with polyoxyethylene ether, sorbitan dioleate and epichlorohydrin) developed by BMR \& Company, Pune, India, was evaluated against late $3^{\text {rd }}$ and early $4^{\text {th }}$ instar larvae of different genera of mosquitoes. The larvae were exposed to different concentrations (0.5-5.0 Ppm) of the formulation along with untreated control. Larvicidal activity of the formulation was also evaluated in field against Anopheles, Culex, and Aedes mosquitoes. The formulation was diluted with equal volumes of water and applied @ $140 \mathrm{mg}$ a.i. $/ \mathrm{m}^{2}$ to different mosquito breeding sites with the help of pre calibrated knapsack sprayer. Larval density was determined at pre and post application of the formulation using a standard dipper.

Results: Median lethal concentration $\left(\mathrm{LC}_{50}\right)$ of the formulation against Anopheles stephensi, Culex quinquefasciatus and Aedes aegypti was found to be $1.6,1.8$ and $1.7 \mathrm{ppm}$ respectively. $L C_{50}$ values of the formulation stored at $26^{\circ} \mathrm{C}, 40^{\circ} \mathrm{C}$ and $45^{\circ} \mathrm{C}$ for 48 hours against Ae. aegypti were 1.7, I.7, $1.8 \mathrm{ppm}$ while $\mathrm{LC}_{90}$ values were $3.7,3.7$ and $3.8 \mathrm{ppm}$ respectively. Further no significant difference in $\mathrm{LC}_{50}$ and $\mathrm{LC}_{90}$ values of the formulation was observed against Ae. aegypti during 18 months storage period at room temperature. An application of the formulation at the rate of $140 \mathrm{mg}$ a.i. $/ \mathrm{m}^{2}$ in different breeding sites under natural field conditions provided $98.1 \%$ reduction of Anopheles larvae on day I; thereafter $100 \%$ reduction was recorded up to week I and more than $80 \%$ reduction up to week 3 , while percent reduction against Culex larvae was $95.5 \%$ on day I, and thereafter $80 \%$ reduction was achieved up to week 3 . The formulation also showed $95.1 \%$ and, $99.7 \%$ reduction of Aedes larvae on day I and day 2 respectively; thereafter 100\% larval control was observed up to day 7.

Conclusion: The neem oil formulation was found effective in controlling mosquito larvae in different breeding sites under natural field conditions. As neem trees are widely distributed in India, their formulations may prove to be an effective and eco-friendly larvicide, which could be used as an alternative for malaria control. 


\section{Background}

Mosquitoes transmit serious human diseases like malaria, filariasis, Japanese encephalitis, dengue haemorrhagic fever and yellow fever causing millions of deaths every year [1]. Extensive use of chemical insecticides for control of vector borne diseases has created problems related to physiological resistance to vectors, adverse environmental effects, high operational cost and community acceptance [2]. Numerous plant products have been reported either as insecticides for killing larvae or adult mosquitoes or as repellents for mosquito biting and are one of the best alternatives for mosquito control $[2,3]$.

Neem trees, (Azadirachta indica) native of India, belonging to family Meliaceae are fast growing evergreen trees ranging in height from $12-24 \mathrm{~m}$. They are widespread in tropical and subtropical regions of the world, including semiarid and wet- tropical regions [4]. Neem seeds contain approximately 99 biologically active compounds of which azadirachtin, nimbin, nimbidin and nimbolides are major molecules. Many of these derived products have antifeedancy, ovicidal activity, fecundity suppression besides insect growth regulation and repellency against insects [5-10]. Neem products have low toxicity to birds, fish and mammals and are less likely to induce resistance due to their multiple mode of action on insects. In addition to this, insect growth regulatory activity of neem weakens the cuticle defence system of the larvae causing easy penetration of pathogenic organisms into insect system. Azadirachtin, a biologically active compound has been promoted as a new insecticide that is considered more eco- friendly than synthetic insecticides. The pesticidal efficacy, environmental safety and public acceptability of neem and its products for control of crop pests has led to its adoption into various mosquito control programmes $[8,11]$.

The present study was aimed to determine the larvicidal potential of the emulsified neem oil formulation against different mosquito genera under natural field conditions in India.

\section{Methods}

\section{Neem oil formulation}

The test formulation was an emulsified concentrate containing $0.15 \% \mathrm{w} / \mathrm{v}$ azadirachtin, polyoxyethylene ether (emulsifier), sorbitan dioleate (surfactant) and epichlorohydrin (used as a stabiliser to protect the degradation of the formulation under exposure to sun light.), developed by BMR \& Company, Pune, India was evaluated against late $3^{\text {rd }}$ and early $4^{\text {th }}$ instar larvae of different genera of mosquitoes.

\section{Larvicidal bioassay}

Larvicidal bioassay of the formulation was performed on late $3^{\text {rd }}$ and early $4^{\text {th }}$ instar larvae of Anopheles stephensi, a primary vector of urban malaria,Culex quinquefasciatus a common vector of filariasis, and Aedes aegypti a common vector of dengue, dengue haemorrhagic fever and yellow fever. The larvae were obtained from laboratory-established colony as described earlier [12]. Twenty-five larvae were released into $500 \mathrm{ml}$ glass beakers containing $250 \mathrm{ml}$ distilled water. The larvae were provided a mixture of dog biscuit and yeast powder in a 3:2 ratio as nutrients and supplemented with different concentrations ( 0.5 to 5.0 $\mathrm{ppm}$ ) of the formulation. The experiments were carried out at $26^{\circ} \mathrm{C} \pm 2{ }^{\circ} \mathrm{C}$. Five replicates of each concentration were run under the same microclimatic conditions along with untreated control. Mortality of larvae was monitored at 24 hours. The percent corrected mortality was calculated using Abbott's formula [13] and Log probit analysis was used to determine the median lethal concentration $\left(\mathrm{LC}_{50}\right) / 90 \%$ lethal concentration $\left(\mathrm{LC}_{90}\right)$ of the formulation.

\section{Stability test}

Larvicidal bioassay of the neem oil-based formulation stored at $26^{\circ} \mathrm{C}, 40^{\circ} \mathrm{C}$ and $45^{\circ} \mathrm{C}$ for $48 \mathrm{hrs}$ was evaluated against $A e$. aegypti at different concentration (0.5-5.0 ppm) as per the method reported above. Five replicates of each concentration were run under the same microclimatic conditions along with untreated control. A total of 100 larvae of Ae. aegypti were exposed against each concentration. Further bioassay test of the neem oil formulation of different concentrations $(0.5-5.0 \mathrm{ppm})$ stored at room temperature $\left(26^{\circ} \mathrm{C} \pm 2{ }^{\circ} \mathrm{C}\right)$ was evaluated against Ae. aegypti larvae at three months interval period for 18 months. Three replicates of each concentration were carried out along with control.

\section{Field evaluation of larvicidal activity}

Field evaluation of larvicidal activity of the neem oil formulation was carried out in two districts of Uttar Pradesh viz. Mathura and Kanpur and district Hardwar of the state of Uttarakhand. Initially a survey was carried out to ascertain the suitability of different breeding habitats of target species for the trial. Larvicidal efficacy was carried out against late $3^{\text {rd }}$ and early $4^{\text {th }}$ instar larvae of different genera of mosquitoes under natural field conditions.

Larval density was determined using standard dipper (300 $\mathrm{ml}$ capacity with $9 \mathrm{~cm}$ diameter) method. Treatment dose (140 $\mathrm{mg}$ a.i. $/ \mathrm{m}^{2}$ ) of the formulation was determined on the basis of the results of laboratory evaluation carried out against $C x$. quinquefasciatus and Ae. aegypti [14]. Five liters of the neem oil formulation was mixed with equal volume of water to make a uniform suspension and applied to 53 $\mathrm{m}^{2}$ surface area of breeding habitats through precalibrated knapsack sprayer.

Larval density/dip was recorded a day before application for both experimental and control habitats, thereafter 
observations were recorded at 24,48 and $72 \mathrm{hr}$ of post application. Further observations were made at weekly intervals for 3 weeks. Percent reduction was calculated for $3^{\text {rd }} \& 4^{\text {th }}$ instar larvae and pupae using the formula.

$$
\% \text { Reduction }=100-\frac{\mathrm{C}_{\mathrm{I}} \times \mathrm{T}_{2}}{\mathrm{C}_{2} \times \mathrm{T}_{1}} \times 100
$$

$\mathrm{C}_{1}, \mathrm{C}_{2}$ are pre-treatment, post-treatment larval density in control whereas $T_{1}, T_{2}$ are pre-treatment post-treatment, immature density in experimental habitats respectively.

\section{Results}

\section{Laboratory study}

Mean $\mathrm{LC}_{50}$ and $\mathrm{LC}_{90}$ values ( $95 \%$ confidence limits) of the neem oil formulation against An. stephensi, Cx. quinquefasciatus and $A e$, aegypti are given in Table 1 . Mean $\mathrm{LC}_{50}$ values of the formulation were 1.6, 1.8 and $1.7 \mathrm{ppm}$ while $\mathrm{LC}_{90}$ were $3.4,3.5$ and $3.7 \mathrm{ppm}$ against An. stephensi, $C x$. quinquefasciatus and Ae. aegypti respectively. Results of stability test of the neem oil based formulation stored at different temperatures against Ae. aegypti are given in Table 2. $\mathrm{LC}_{50}$ values of the biopesticide stored at $26^{\circ} \mathrm{C}, 40^{\circ} \mathrm{C}$ and $45^{\circ} \mathrm{C}$ for 48 hours were $1.7,1.7,1.8 \mathrm{ppm}$ while $\mathrm{LC}_{90}$ values recorded were 3.7, 3.7 and 3.8 ppm respectively. Mean $\mathrm{LC}_{50}$ and $\mathrm{LC}_{90}$ of the formulation during 18 months storage period at room temperature against Aedes aegypti is shown in Figure 1. No significant difference $(P>0.5)$ in $\mathrm{LC}_{50}$ and $\mathrm{LC}_{90}$ value of the formulation was observed.

\section{Field study}

Before start of the study, a preliminary survey of various breeding sites of mosquitoes was carried out. In all 73 breeding sites (factory scraps) were surveyed inside the Ordnance factory, Kanpur, out of which 67 sites were found positive $(91.8 \%)$ for Aedes larvae. Larvae collected from these breeding sites were identified as Ae. aegypti and Ae. albopictus. A survey of different breeding sites such as

Table I: Larvicidal activity of neem oil formulation against mosquito in laboratory

\begin{tabular}{lcc}
\hline Species & \multicolumn{2}{c}{ Larvicidal activity $(\mathbf{p p m})$} \\
\cline { 2 - 3 } & $\begin{array}{c}\mathbf{L C}_{50} \\
(\text { Mean } \pm \mathrm{sd})\end{array}$ & $\begin{array}{c}\mathbf{L C}_{90} \\
(\text { Mean } \pm \mathrm{sd})\end{array}$ \\
\hline Anopheles stephensi & $\begin{array}{c}1.6 \pm 0.4 \\
(1.1-2.5)^{*}\end{array}$ & $\begin{array}{c}3.4 \pm 0.5 \\
(2.7-4.0)\end{array}$ \\
\hline Culex quinquefasciatus & $\begin{array}{c}1.8 \pm 0.5 \\
(1.2-2.6)\end{array}$ & $\begin{array}{c}3.5 \pm 0.6 \\
(2.8-4.2)\end{array}$ \\
\hline Aedes aegypti & $\begin{array}{c}1.7 \pm 0.3 \\
(1.3-2.1)\end{array}$ & $\begin{array}{c}3.7 \pm 0.5 \\
(3.1-4.3)\end{array}$ \\
\hline
\end{tabular}

Water depth: $2.5 \mathrm{~cm} ; * 95 \%$ confidence limits; Number of replicates: 5
Table 2: Larvicidal activity of neem oil formulation against Aedes aegypti at different storage temperature

\begin{tabular}{lll}
\hline Storage temperature & \multicolumn{2}{c}{ Larvicidal activity (mean) } \\
\cline { 2 - 3 } & $\mathbf{L C}_{50}$ & LC $_{90}$ \\
\hline $26 \pm 2{ }^{\circ} \mathrm{C}$ & $1.7 \pm 0.5$ & $3.7 \pm 0.8$ \\
\hline $40^{\circ} \mathrm{C}$ & $1.7 \pm 0.6$ & $3.7 \pm 0.5$ \\
\hline $45^{\circ} \mathrm{C}$ & $1.8 \pm 0.4$ & $3.8 \pm 0.6$ \\
\hline
\end{tabular}

Number of each replicate: 3

tanks, pits, drains were also carried at Indian Oil Corporation, Mathura and Bharat Heavy Electricals Limited, Hardwar for Culex and Anopheles breeding. Culex and Anopheles larvae collected from these sites were identified as $C x$. quinquefasciatus, An. culicifacies and An. subpictus respectively.

Mean percent reduction of larval density against $C x$. quinquefasciatus and anophelines in different breeding habitats are given in Table 3. In pits, percent reduction of Culex larvae was 95.9, 90.2, 87.2 on days $1,2,3$ respectively of post application, while more than $70 \%$ reduction was observed up to week 3 . In tanks $91.6 \%-92.4 \%$ reduction of Culex larvae was observed up to day 7 of post application thereafter $80.7 \%$ reduction was noted up to week 3, while in drains there was more than $90 \%$ larval control up to day 7 and remained above $75 \%$ up to week 3 . An effective control of late instars anopheline larvae in tanks was observed with $98.2 \%$ reduction on day 1 , followed by $100 \%$ reduction up to day 7 and more than $75 \%$ reduction till week 3 . In pits, $96.2 \%$ control was recorded on day $1,100 \%$ up to day 7 and more than $75 \%$ reduction up to week 3 . The mean percent reduction of Culex larvae was $89.9-95.5 \%$ up to day 7 followed by $79.7-85.7 \%$ up to week 3, while for Anopheles larvae mean percent reduction was $90.4-100 \%$ up to day 7 followed by $83.8-90.4 \%$ up to week 3 (Figure 2).

Larvicidal activity of the formulation against Aedes larvae in different breeding sites is given in Table 4. There was $85.2 \%$ to $98.1 \%$ reduction of Aedes larvae on day 1 of post application of the neem oil formulation, thereafter $99.7 \%$ to $100 \%$ reduction was recorded up to day 7 .

\section{Discussion}

Neem trees are found throughout India with a myriad of uses in medicine, as well as pest control [4]. Neem-based pesticides are now extensively used in agriculture practices all over the world. It contains azadirachtin, which is a predominant insecticidal active ingredient, having antefeedent, ovipositional deterrence repellency, growth 


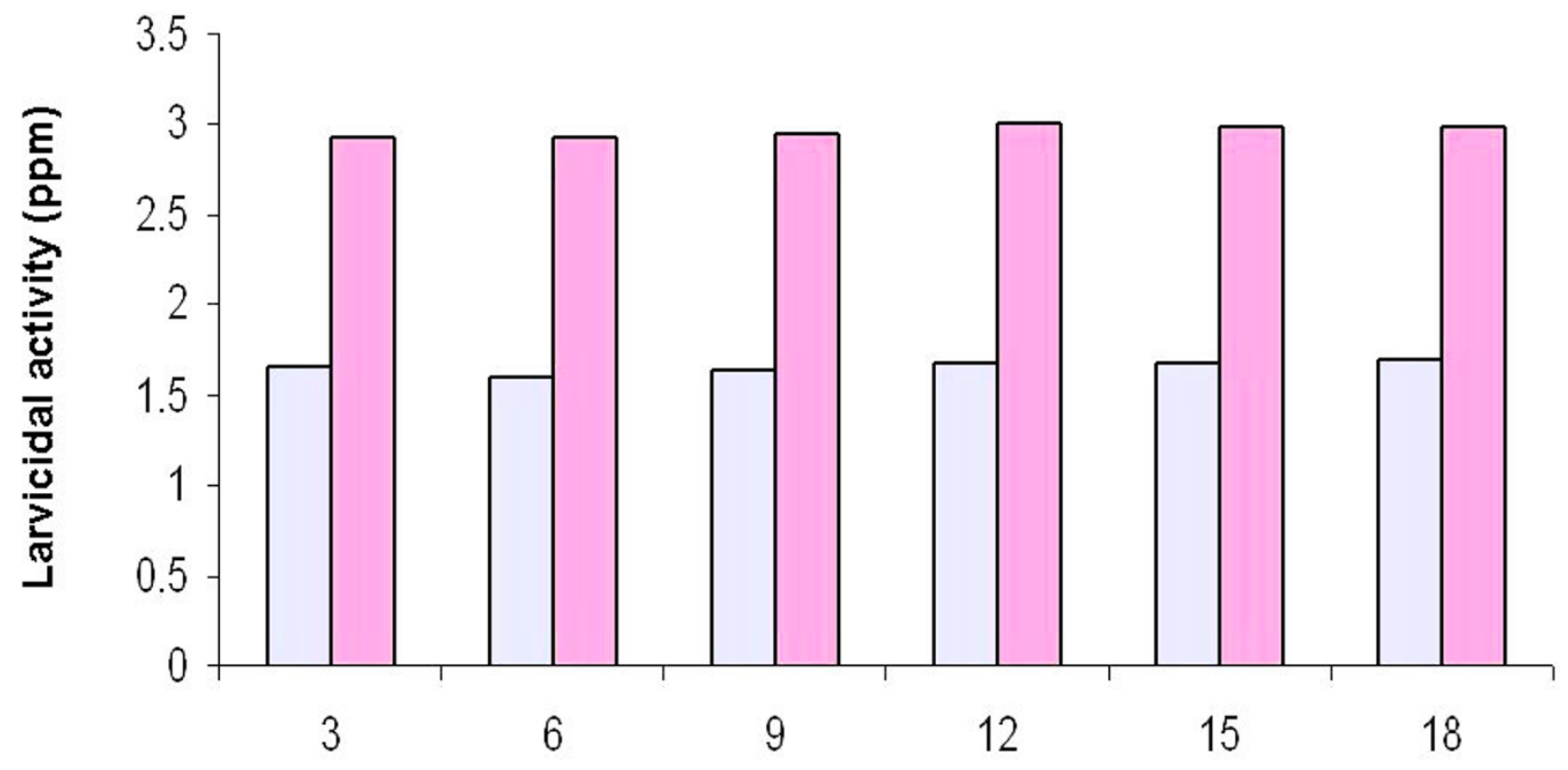

$\square$ LC50 $\square$ LC90

Months (Storage Period)

Figure I

Stability test of the neem oil formulation against Aedes aegypti.

disruption, sterility and larvicidal action against insects [6]. There are various reports of control of mosquito breeding under field conditions. An emulsion of neem oil in water was found to be effective in controlling breeding of Cx. quinquefasciatus, An. stephensi and Ae. aegypti in pools, tanks and coolers up to 2 to 3 weeks [15], whereas an application of neem cake powder resulted in drastic reduction in the late instar larvae and pupae of culicine mosquitoes in paddy field [16].

Mean $\mathrm{LC}_{50}$ values were 1.6, 1.8 and 1.7 ppm against $A n$. stephensi, Cx. quinquefasciatus and Ae. aegypti, while $\mathrm{LC}_{90}$

Table 3: Larvicidal activity of neem oil formulation against mosquitoes larvae in field

\begin{tabular}{|c|c|c|c|c|c|c|c|c|}
\hline \multirow[t]{2}{*}{ Mosquito species } & \multirow[t]{2}{*}{ Breeding sites } & \multirow{2}{*}{$\begin{array}{l}\text { Pre treatment } \\
\text { density }\end{array}$} & \multicolumn{6}{|c|}{ Percent reduction of larval density (mean $\pm \mathrm{sd}$ ) } \\
\hline & & & Day-I & Day-2 & Day-3 & Week-I & Week-2 & Week-3 \\
\hline \multirow[t]{4}{*}{ Culex } & Pits & $28.9 \pm 10.6$ & $95.9 \pm 3.5$ & $90.2 \pm 6.9$ & $87.2 \pm 11.0$ & $87.5 \pm 8.2$ & $85.9 \pm 8.0$ & $80.5 \pm 7.3$ \\
\hline & Tanks & $26.8 \pm 11.5$ & $91.9 \pm 5.8$ & $93.2 \pm 3.2$ & $97.7 \pm 1.9$ & $92.4 \pm 8.0$ & $86.2 \pm 8.2$ & $80.7 \pm 9.2$ \\
\hline & Drains & $115.7 \pm 64.6$ & $99.4 \pm 0.6$ & $98.8 \pm 1.2$ & $98.6 \pm 1.4$ & $84.9 \pm 4.6$ & $85.0 \pm 11.8$ & $77.8 \pm 11.0$ \\
\hline & & & $95.5 \pm 4.1$ & $94.1 \pm 4.3$ & $94.5 \pm 5.5$ & $89.9 \pm 2.5$ & $85.7 \pm 0.8$ & $79.7 \pm 1.6$ \\
\hline \multirow[t]{4}{*}{ Anopheles } & Pits & $13.5 \pm 7.5$ & $96.2 \pm 4.5$ & 100 & 100 & 100 & $85.4 \pm 14.1$ & $76.6 \pm 9.6$ \\
\hline & Tanks & $10.4 \pm 5.7$ & $98.2 \pm 1.8$ & 100 & 100 & 100 & $87.0 \pm 9.7$ & $77.7 \pm 10.0$ \\
\hline & Drains & $13.0 \pm 6.7$ & 100 & 100 & 100 & 100 & $98.7 \pm 1.3$ & $97.0 \pm 3.0$ \\
\hline & & & $98.1 \pm 1.9$ & 100 & 100 & 100 & $90.4 \pm 7.2$ & $83.8 \pm$ II.5 \\
\hline
\end{tabular}




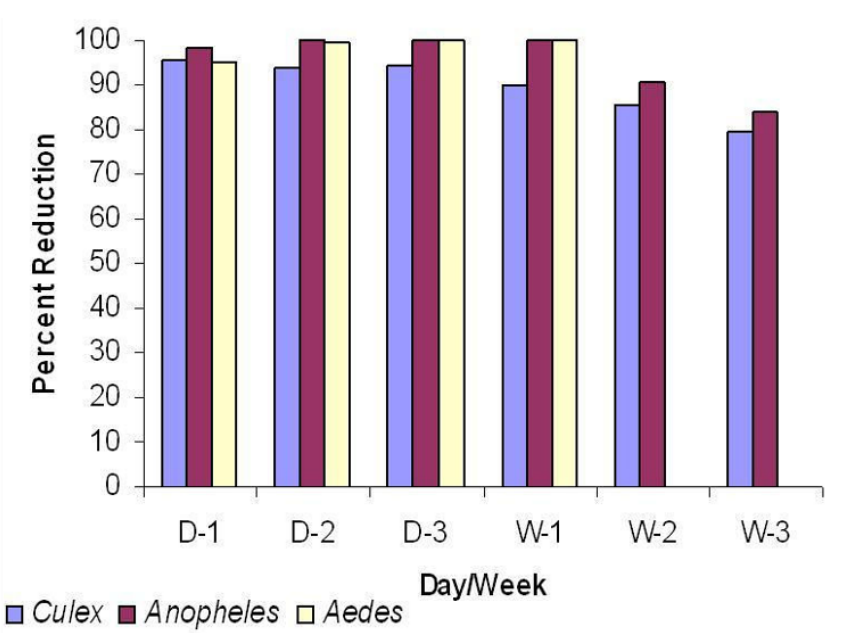

Figure 2

Impact of larvicidal activity of the neem oil formulation against mosquito larvae.

were 3.4, 3.5 and 3.7 ppm respectively. $\mathrm{LC}_{50}$ of the formulation stored at $26^{\circ} \mathrm{C}, 40^{\circ} \mathrm{C}$ and $45^{\circ} \mathrm{C}$ for 48 hours were $1.7,1.7,1.8$ ppm while $\mathrm{LC}_{90}$ values were $3.7,3.7$ and 3.8 ppm respectively which revealed that there was no difference in the biopestcidal activity of the neem oil formulation at different storage temperatures. No significant difference of larvicidal activity of the formulation was also observed during 18 months storage period at room temperature.

In the present study an application of the formulation at the rate of $140 \mathrm{mg}$ a.i./ $\mathrm{m}^{2}$ in pits, tanks and drains provided above $90 \%$ reduction of Culex larvae up to week 1 and thereafter $80 \%$ reduction up to week 3, whereas
$100 \%$ reduction was observed in Anopheles larvae up to week 1 , after that more than $80 \%$ reduction was recorded up to week 3 .

Dhar et al [17] demonstrated the inhibitory effect of neem oil volatiles on gonotropic cycle in An. stephensi and An. culicifacies. A neem oil formulation containing 32\% neem seed oil (an equivalent of $0.03 \%$ azadirachtin), an emulsifier (5\%) and 63\% iso propanol (solvent) was investigated for its larvicidal activities against An. gambiae [18]. It was toxic to mosquito larvae with $\mathrm{LC}_{50}$ value of $11 \mathrm{ppm}$ and also reported to possess insect growth regulators. Gianotti and co workers [19] used powdered seeds of neem trees and applied twice a week to known breeding sites for An. gambiae at the rate of $10 \mathrm{gm} / \mathrm{m}^{2}$ of pool surface area for effective larval control. Azadirachtin acts as anti-ecdysteroid and kills larvae by growth inhibition effect [20]. In the present investigation, neem oil formulation was found effective to control mosquito larvae in different breeding habitats under natural field conditions and more than $80 \%$ reduction of Anopheles, Culex and Aedes larvae was observed up to three weeks of post application.

Neem-based biopesticides and neem extracts have a wide range of effects against insect pests including repellence, feeding, toxicity, sterility and growth regulator activity and are relatively safe towards non- target biota with only minimal risk of direct adverse effects on aquatic biota from contamination of water bodies [21,22]. Allelochemicals such as azadirachtin, nimbin, nimbidin, nimbolides, nimolic acid, salannin, melianttriol, azadirachtol present in neem affect the biochemical and physiological processes of insect system and nullify the insect detoxification mechanism thereby not allowing the pest to develop

Table 4: Larvicidal activity of neem oil formulation against Aedes mosquitoes in field

\begin{tabular}{|c|c|c|c|c|c|c|}
\hline \multirow[t]{2}{*}{ Breeding sites } & \multirow[t]{2}{*}{ Pre treatment larval density } & \multirow[t]{2}{*}{$\mathrm{pH}$} & \multicolumn{4}{|c|}{ Percent reduction of larval density (Mean $\pm s d$ ) } \\
\hline & & & Day-1 & Day-2 & Day-3 & Day-7 \\
\hline Tyres & $10.3 \pm 4.1$ & $8.0-9.0$ & $94.3 \pm 4.5$ & $98.6 \pm 1.4$ & 100 & 100 \\
\hline Machinery scraps & $14.5 \pm 8.6$ & $8.0-9.0$ & $96.0 \pm 3.0$ & 100 & 100 & 100 \\
\hline Iron container & $19.2 \pm 5.7$ & 8.5 & $98.1 \pm 1.5$ & 100 & 100 & 100 \\
\hline Iron box & $11.0 \pm 6.0$ & $8.0-8.5$ & $96.9 \pm 2.0$ & 100 & 100 & 100 \\
\hline Iron tanks & $9.0 \pm 2.6$ & $8.0-8.5$ & $85.2 \pm 6.5$ & 100 & 100 & 100 \\
\hline \multirow[t]{2}{*}{ Plastic scrap } & 6.0 & 8.5 & 100 & 100 & 100 & 100 \\
\hline & & & $95.1 \pm 5.2$ & $99.7 \pm 0.3$ & 100 & 100 \\
\hline
\end{tabular}

Total replicates: 21 
resistance. As an emulsifiable concentrate, the neem oil formulation had greatly reduced sized particles and evenly mixed within the water column with a few suspended particles on the water surface. The spread of these fine particles probably increased the efficacy of formulation.

Control of mosquito larvae becomes a very pertinent issue in controlling the rapid replication of mosquitoes in management of vector- borne diseases. In the present study, neem oil formulation showed promising larvicidal activity against important vectors of malaria, filaria, dengue, dengue haemorrhagic fever, yellow fever and chikungunya. Development of resistance in temephos and Bacillus thuringiensis is a matter of concern for operational use as larvicides. Although the present formulation may be more costly than other larvicidal agents, such as temephos and $B$. thuringiensis, it has the advantage of being ecofriendly, effective and ability to prevent the development of pest resistance.

\section{Conclusion}

The neem oil formulation was found effective in controlling mosquito larvae in different breeding sites under natural field conditions. Neem oil formulations are relative less toxic, eco-friendly and insects are unable to develop resistance and may be used as an alternative to other pesticides for control of vector- borne diseases.

\section{Competing interests}

The authors declare that they have no competing interests.

\section{Authors' contributions}

VD: designed the study protocols, directed the larvicidal research. ACP: designed and performed the larvicidal trials collected and analysed the data. KR: Editing the manuscript

AG: Performed larvicidal trials drafted the manuscript TS: Field trials of the larvicide. APD; Coordination and organizational help to conduct the study. All authors read and approved the final manuscript.

\section{Acknowledgements}

The investigators are thankful to Director General, Indian Council of Medical Research and Director, National Institute of Malaria Research for granting permission to under take the study. We are also thankful to BMR \& Co. Pune for sponsoring the project and supply of the formulation for the trials.

\section{References}

I. Mittal PK, Subbarao SK: Prospects of using herbal products in the control of mosquito vectors. ICMR Bull 2003, 33:I-10.

2. Brown AWA: Insecticide resistance in mosquitoes; a pragmatic review. J Am Mosq Control Assoc 1986, 2: I 23-I40.

3. Sukumar K, Perich MJ, Boobar LR: Botanical derivative in mosquito control: A Review. J Am Mosq Control Assoc 1991, 7:2 10-237.

4. National Research Council: Neem: a tree for solving global problems. In Report of an adhoc panel of the Board on Science and
Technology for International Development National Academy Press, Washington, DC; 1992.

5. Isman MB: Botanical insecticides, deterrent and repellents in modern agriculture and an increasingly regulated world. Ann Rev Entomic 2006, 51:45-66.

6. Schmutterer H: Properties of natural pesticides from the neem tree, Azadirachta indica. Ann Rev Entomol 1990, 35:27I-297.

7. Locantoni L, Guisti F, Cristofaro M, Pasqualini L, Esposito F, Lupetti $P$, Habluetzel A: Effect of neem extract on blood feeding oviposition and oocyte ultra structure in Anopheles stephensi Liston (Diptera: Culicidae). Tissue Cell 2006, 38:36I-37I.

8. Su T, Mulla MS: Antifeedancy of neem products containing Azadirachtin against Culex tarsalis and Culex quinquefasciatus (Diptera: Culicidae). J Vector Ecol 1998, 23: I |4-I22.

9. Sharma VP, Dhiman RC: Neem oil as a sand fly (Diptera: Psychodidae) repellent. J Am Mosq Control Assoc 1993, 9:364-366.

10. Schmutterer $\mathrm{H}$ : The neem tree (Azadirachta indica) and other Meliceous plants. In Source of Unique Natural Products for Integrated Pest Management, Medicine, Industry and other porposes Ist edition. Mumbai: Neem Foundation; 2002.

II. Su T, Mulla MS: Ovicidal activity of neem products (azadirachtin) against Culex tarsalis and Culex quinquefasciatus (Diptera; Culicidae). J Am Mosq Control Assoc 1998, 14:204-209.

12. World Health Organization: Instruction for determining the susceptibility or resistance of mosquito larvae. 198I.

13. Abbott WS: A method of computing the effectiveness of an insecticide. J Econ Entomol 1925, 18:265-266.

14. World Health Organization: Chemical methods for the control of vector and pests of public health importance Edited by: Chavassee DC, Yap $\mathrm{NH}$. WHO; 1997.

15. Batra CP, Mittal PK, Adak T, Sharma VP: Efficacy of neem-water emulsion against mosquito immatures. Indian J Malariol 1998, 35:|15-2|.

16. Rao DR, Reuben R, Venugopal MS, Nagasampgi BA, Schmutterer H: Evaluation of neem - Azadirachta indica with and without water management for the control of culicine mosquito larvae in rice field. Med Vet Entomol 1992, 6:318-324.

17. Dhar R, Dawar H, Garg SS, Basir F, Talwar GP: Effect of volatiles from neem and other natural products on gonotropic cycle and oviposition of Anopheles stephensi and An. culicifacies. J Med Entomol 1996, 33:195-201.

18. Okumu FO, Knols BG], Fillinger U: Larvicidal effects of a neem (Azadirachta indica) oil formulation on the malaria vector Anopheles gambiae. Malar J 2007, 6:63.

19. Gianotti RL, Bomblies A, Dafalla M, Issa-Arzika I, Duchemin JB, Eltahir EAB: Efficacy of local neem extracts for sustainable malaria vector control in an African village. Malar J 2008, 7:138.

20. Zebit CPW: Effect of some crude and Azadirachta-enriched neem (Azadirachta indica) seed kernel extracts of larvae of Aedes aegypti. Entomol Exp Appl 1984, 35: I I-I6.

21. Kreutzweiser DP: Non-target effects of neem based insecticides on aquatic invertebrates. Ecotoxicol Env Safety 1997, 36:109-117.

22. Goektepe I, Portier R, Ahmedna M: Ecological risk assessment of neem based pesticides. J Env Sci Hlth B 2004, 39:3 I I-320.

Publish with Biomed Central and every scientist can read your work free of charge

"BioMed Central will be the most significant development for disseminating the results of biomedical research in our lifetime. "

Sir Paul Nurse, Cancer Research UK

Your research papers will be:

- available free of charge to the entire biomedical community

- peer reviewed and published immediately upon acceptance

- cited in PubMed and archived on PubMed Central

- yours - you keep the copyright 